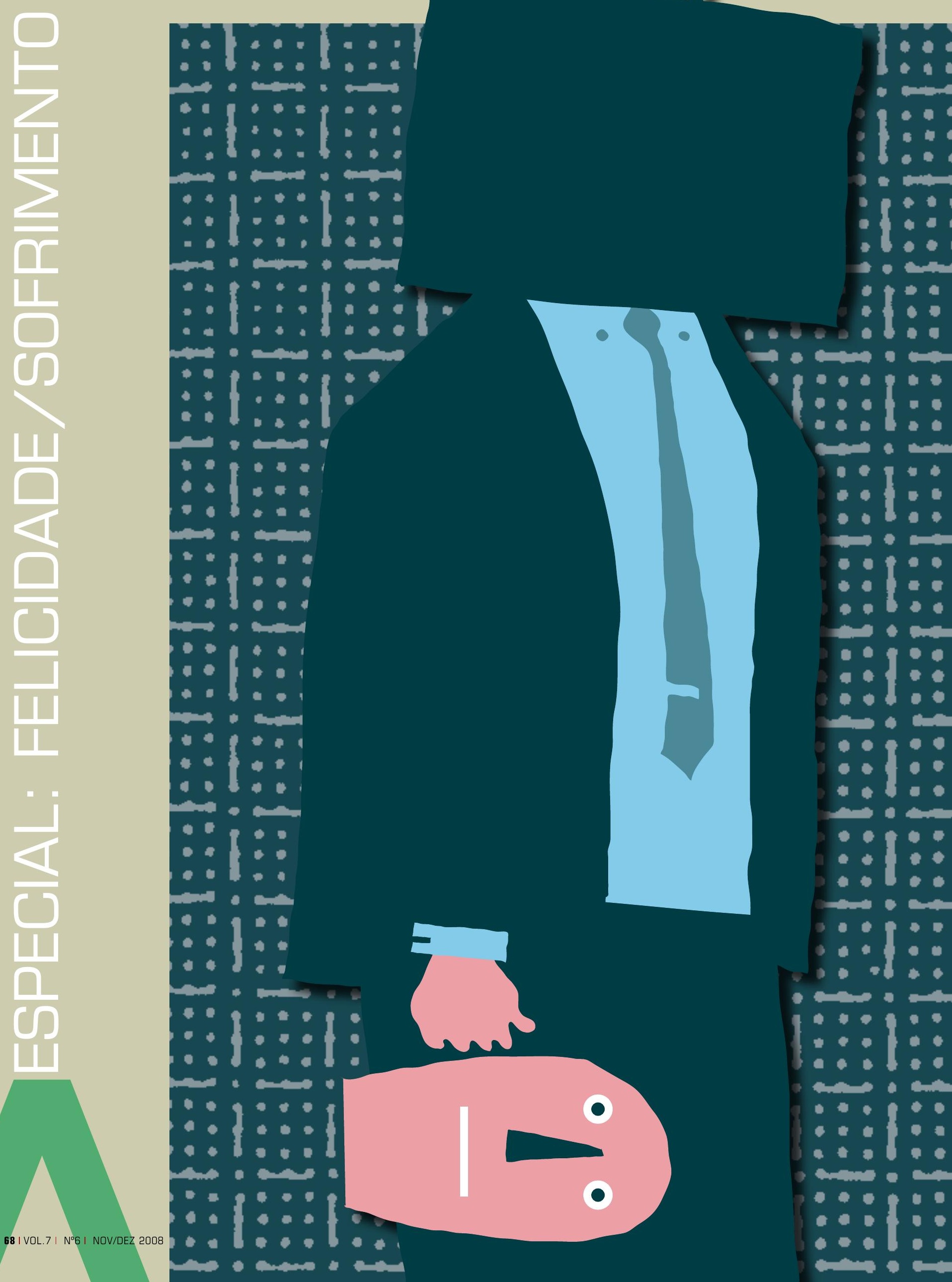




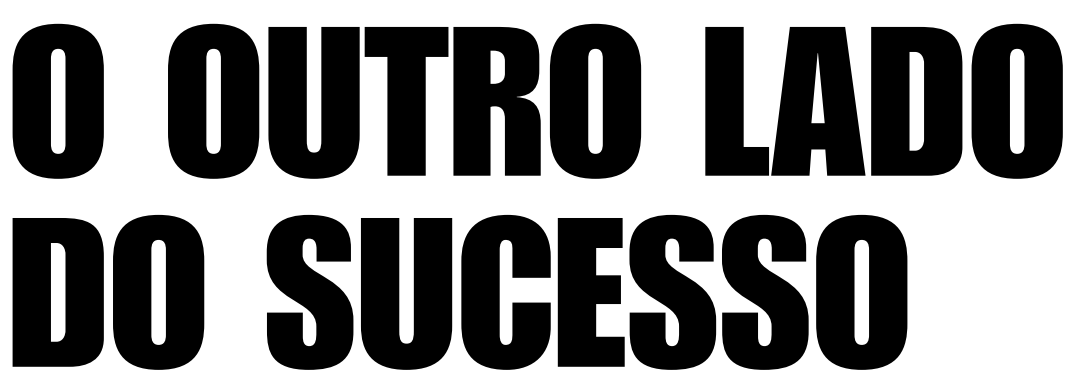

Apesar de o trabalho ser uma das principais vias para a realização humana, quando ele impede a inclusão de outras dimensões importantes, como a família e os relacionamentos, as conseqüências podem ser catastróficas POR MARCELO PINHEIRO 
Ainda que o verniz do sucesso profissional possa projetar uma imagem de perfeição nos diversos aspectos da vida, inevitavelmente os dramas pessoais fazem parte do dia-a-dia das pessoas. As organizações em geral negligenciam aquilo que não possui ligação direta com a produtividade e a lucratividade e valorizam a priorização absoluta do trabalho em detrimento das outras áreas da vida - familiar, social, espiritual e sexual.

É claro que os funcionários de todos os níveis hierárquicos de uma organização podem conseguir progresso na carreira dedicando longas horas ao trabalho; contudo, isso às vezes ocorre à custa da vida particular, na forma de uma disponibilidade excessiva ao trabalho - por exemplo, jornadas de 12 horas por dia ou mais no próprio local de trabalho, e mais umas tantas fora dele, conectados por laptops e palmtops, inclusive nos finais de semana. Ao mesmo tempo, parece que há uma aceitação, por parte de muitos profissionais, da idéia de que o sucesso profissional exige um alto preço e que este ocorre a partir da deterioração da vida pessoal. Por que esses profissionais aceitam essa troca?

DEDICAÇÃO EXAGERADA. Recentemente, participei de uma reunião para a celebração de tempo de serviço de um grupo de funcionários de uma empresa. Tratava-se de uma ocasião particularmente especial, pois entre os homenageados havia profissionais comemorando de cinco a 35 anos de empresa! Os funcionários prestigiados eram convidados a se juntarem aos seus gerentes para receber um presente comemorativo, logo após terem ouvido um rápido discurso sobre a importância de sua contribuição à empresa ao longo dos anos.

Esse tipo de evento freqüentemente gera um entusiasmo contagiante, que surge a partir do reconhecimento do trabalho das pessoas, especialmente das que se dedicaram por tanto tempo a uma mesma organização. Porém, entre os elogios ao empenho e à contribuição, os gestores ressaltavam a dedicação quase exclusiva de seus subordinados à corporação, valorizando o fato de eles terem priorizado a vida profissional em detrimento das demais dimensões da vida.

Essa experiência me levou a pensar sobre um mal-estar latente generalizado nas organizações. Ele emerge do sentimento de angústia das pessoas que investem grandes esforços para lidar, ao mesmo tempo, com as altas demandas profissionais e com os outros aspectos igualmente importantes da vida. Se, por um lado, as empresas fazem exigências cada vez mais vorazes de desempenho, por outro, há um sentimento de fracasso de alguns profissionais em relação à vida pessoal. 
CONSEQÜÊNCIAS DO EXAGERO. O trabalho é uma das fontes de realizações humanas mais gratificantes, porém não parece saudável que seja considerada a única. Diversos fatores podem levar as pessoas a uma vida de elevada devoção profissional a uma empresa, priorizando o trabalho em detrimento dos demais aspectos igualmente importantes da vida.

Em conversas com funcionários de diferentes níveis de cargos, é possível identificar um relato recorrente acerca do pouco tempo desfrutado com as pessoas que são mais importantes para eles, e como essa ausência é difícil de recuperar. É possível identificar nesses comentários, muitas vezes feitos em tom lamentoso, um sentimento comum dos que optaram por priorizar o trabalho acima da vida particular: a culpa.

$\mathrm{O}$ argumento mais comum é de que a dedicação exagerada à vida profissional serve justamente para garantir uma vida pessoal de alta qualidade para a família e para si próprio. Será mesmo? Temos aqui um paradoxo: o fato é que aquilo que possibilita a esses profissionais os recursos materiais para oferecerem uma vida financeiramente próspera à suas famílias é também o que os afasta delas.

O sentimento de culpa desses profissionais traz muitos significados subjacentes: inicialmente, o de acreditarem ter lesado pessoas que são importantes para eles, e o de que o conforto

\section{Para algumas} pessoas, o trabalho pode ser um álibi para evitar as frustrações de uma vida familiar na qual não conseguem obter gratificações

material proporcionado em contrapartida não foi suficiente para reparar o dano. É verdade que todos temos compromissos financeiros a serem cumpridos, e que a remuneração obtida a partir do trabalho possibilita desde a manutenção da subsistência básica até o desfrute de uma qualidade de vida extremamente privilegiada. Contudo, poderíamos questionar: a vida profissional precisa exigir exclusividade quase absoluta?

SOLIDÃO E CASAMENTO. Outra conseqüência resultante de uma dedicação exclusiva ao trabalho é a solidão - que não se resume apenas à ausência física de amigos ou de um parceiro. 


\section{Muitos profissionais investem} bastante tempo capacitando-se para lidar com assuntos de ordem administrativa e financeira, porém dedicam-se pouco a desenvolver habilidades de relacionamento

Refere-se à lacuna intransponível entre duas pessoas, mesmo quando estão próximas e poderiam desfrutar de alguma intimidade.

Algumas vezes a solidão pode ser uma prática saudável. Todos nós temos necessidade de reservar algum tempo para organizar pensamentos, refletir sobre nossas experiências, planejar nossa vida e nos preparar para tomar decisões. Isolar-se pode ser uma forma de buscar o autoconhecimento. Entretanto, a solidão passa a ser um indicador de conflito quando o indivíduo se vê compelido a ela por não ter desenvolvido relações de afeto fora do ambiente de trabalho.

Como resultado, o indivíduo se volta ainda mais ao trabalho, onde supostamente é capaz de ter relacionamentos e obter estímulos. Devido à natureza competitiva do ambiente de trabalho, torna-se difícil obter nas relações profissionais o mesmo grau de intimidade obtido nas relações familiares ou em outros grupos sociais.
Outro resultado da dedicação excessiva ao trabalho é a perda da vitalidade do casamento. A falta de investimento nas relações afetivas pode inclusive transpor o relacionamento mais imediato entre os parceiros e alcançar os filhos. Não é incomum executivos relatarem que, por terem sido tragados pelas demandas profissionais do dia-a-dia, simplesmente não viram seus filhos crescer. Esse comentário trágico, profundamente doloroso, é quase sempre suplantado pela racionalização de que o esforço todo foi, ao final das contas, para dar melhores condições de vida e instrução aos próprios filhos.

Entretanto, o pai ou a mãe que repentinamente procura estabelecer uma relação afetiva com o filho adolescente após anos de negligência freqüentemente descobre que é muito tarde. Ainda que seja possível melhorar a qualidade do relacionamento no presente, não será mais possível viver a infância perdida dos filhos. $\mathrm{Na}$ 
situação dos casais mais jovens e ainda sem filhos, a dúvida é sobre a postergação do primeiro filho. Essa é uma questão especialmente importante para a mulher, uma vez que o afastamento por licença maternidade pode influenciar negativamente o progresso de sua carreira.

ALTERNATIVAS. Em algum ponto da vida as pessoas se confrontarão com a questão: "Estou vivendo de uma maneira que traga felicidade para mim, bem como para as pessoas que me são importantes?". Alguns se sentem insatisfeitos com o destino que a vida deles tomou e percebem que simplesmente se adaptaram a uma situação adversa. Esse tipo de questionamento é saudável, e indica que pode ter chegado o momento de reavaliar as escolhas.

Um passo importante é conscientizar-se de que há um problema, e que a busca de respostas e certezas absolutas em um ambiente que não possui nenhuma delas torna a empreitada ainda mais difícil. Muitos sofrerão ao procurar o equilíbrio entre as diversas áreas da vida. Para algumas pessoas, o trabalho pode ser um álibi para evitar as frustrações de uma vida familiar na qual não conseguem obter gratificação, assim como as frustrações nos demais papéis sociais, igualmente insatisfatórios. Compreender quais são as origens dessas frus- trações é fundamental para obter progressos na dissolução desses conflitos e ser capaz de desfrutar de bons vínculos de intimidade.

Em geral, os profissionais investem bastante tempo capacitando-se para lidar com assuntos de ordem administrativa e financeira, porém dedicam-se pouco a desenvolver habilidades de relacionamento que são imprescindíveis para uma vida satisfatória. A falta de treinamento em comportamento humano faz com que as pessoas fiquem à deriva no que tange ao enfrentamento e à resolução de conflitos interpessoais. O profissional que triunfa no trabalho à custa de sua vida pessoal tende a ser uma pessoa com vínculos afetivos frágeis, uma vez que a vida social e a familiar exigem relações de transparência em um nível raro de se encontrar no ambiente de trabalho.

A busca de auxílio profissional na figura de um coach, com ênfase nos aspectos da vida profissional, ou de um psicoterapeuta, para as questões mais amplas da vida, pode ser uma alternativa de resultados positivos. Ainda que o trabalho seja verdadeiramente uma das fontes mais poderosas de gratificação em diversos aspectos, é necessário que as pessoas se questionem sobre a vida que escolheram, e que repensem os reais motivos pelos quais se dedicam de maneira tão exagerada ou exclusiva ao trabalho. 